\title{
La Pintura del techo del Teatro Vicó de Jumilla (Murcia). Estudio histórico y material
}

\author{
Sonia Santos Gómez, Margarita San Andrés Moya, Ruth Chércoles
}

Resumen: Las representaciones teatrales constituyeron uno de los ejes de la vida social de la España decimonónica, por lo que durante el siglo XIX se construyeron numerosos inmuebles que necesitaron, asimismo, de mobiliario, enseres $y$ pinturas que configuraran un ambiente suntuoso. Muchas de estas pinturas fueron realizadas al temple de cola sobre lienzo. Un ejemplo de lo citado es la pintura del techo del teatro Vico de la ciudad de Jumilla en Murcia (España) (ca. 1883). Su estudio microanalítico ha revelado los materiales y la metodología de trabajo aplicados en su ejecución, característicos de la pintura decorativa del siglo XIX. Se ha constatado el uso de ciertos pigmentos producidos por la industria moderna europea, acompañados de otros más tradicionales, que entran dentro de la categoría de los pigmentos históricos. Asimismo, resulta destacable la identificación de carbonato cálcico, en forma de creta, en las preparaciones y en la capa pictórica.

Palabras clave: Pintura decorativa, pintura al temple, pigmentos artísticos, carbonato cálcico, creta, microscopía óptica, SEM-EDX

\section{The painting of the ceiling of the Theater Vico Jumilla (Murcia). Historical and material study}

Abstract: The theatrical representations were one of the axes of social life of 19th century in Spain, so during that century were built many buildings that also needed furniture, furnishings and paintings that set a sumptuous atmosphere. Many of these paintings were made in queue on canvas tempera. An example of this is the ceiling painting of the Vico theater in the city of Jumilla in Murcia (Spain) (ca. 1883). Its microanalytical study has revealed the materials and work methodology applied in his execution, which are characteristic of 19th century decorative painting. The use of certain pigments produced by modern European industry, accompanied by more traditional ones, which fall within the category of historical pigments, has been confirmed. Likewise, the identification of calcium carbonate, in the preparations and in the pictorial layer is noteworthy.

Keyword: Decorative painting, tempera painting, artistic pigments, calcium carbonate, chalk, optical microscopy, SEM-EDX

\section{A pintura do teto do Teatro Vicó de Jumilla (Murcia). Estudo histórico e material}

Resumo: As representações teatrais constituíram um dos eixos da vida social da Espanha oitocentista, de modo que durante o século XIX foram construídos inúmeros edifícios que precisavam de móveis, equipamentos e pinturas que configuravam um ambiente suntuoso. Muitas destas pinturas foram realizadas a têmpera de cola sobre tela. Um exemplo disso é a pintura no teto do teatro Vico, na cidade de Jumilla, em Múrcia (Espanha) (ca. 1883). O seu estudo micro analítico revelou os materiais e a metodologia de trabalho aplicados na sua execução, característicos da pintura decorativa do século XIX. Constatou-se o uso de certos pigmentos produzidos pela indústria moderna europeia, acompanhados de outros mais tradicionais, que se enquadram na categoria de pigmentos históricos. Da mesma forma, destaca-se a identificação do carbonato de cálcio, nas preparações e na camada pictórica.

Palavras-chave: Tinta decorativa, tinta a têmpera, pigmentos artísticos, carbonato de cálcio, cré, microscopia ótica, SEM-EDX 


\section{Introducción}

A lo largo de la historia, la pintura al temple sobre lienzo ha tenido diversas utilidades, como cubrir los altares en época de Cuaresma, decorar doseles de cama, túmulos, monumentos de Semana Santa, y paredes de las casas. Normalmente se utilizaba cola animal como aglutinante (aunque a veces también se empleaba huevo) y, si se aplicaba una capa de preparación, ésta solía ser de cola, habitualmente mezclada con yeso en el caso de España (Santos 2017).

Algunos de estos usos decorativos tienen ejemplos significativos en palacetes y casas principales de burguesía y nobleza, así como en otros edificios emblemáticos para el esparcimiento y encuentro social de la España decimonónica. Es el caso de teatros, casinos y otros centros socio-culturales, cuyas estancias eran decoradas con enseres, mobiliario y pinturas; todo ello con el objetivo de conferir a estas estancias un ambiente suntuoso.

Estos temples que iban a estar fijos solían ser adheridos al muro, con lo que la obra adquiere el carácter de pintura mural. Hilaire Hiler, en su tratado The Painter's Pocket-Book of Methods and Materials (primera ed. 1937), denomina la pintura adherida a los muros como Marouflage e indica fue muy popular en el siglo XIX. (Hiler 1970: 157-158). Como ejemplos de estos temples, pueden citarse el de la bóveda del Salón de Plenos del Senado Antiguo, del siglo XIX o el techo del patio de butacas del Teatro Calderón de Motril, tradicionalmente atribuida a Francisco Muros y ejecutada poco antes del otoño de 1881.

Aunque efectivamente la técnica del temple sobre lienzo ha sido empleada como pintura decorativa en paredes, también se ha utilizado el óleo en pintura decorativa de grandes dimensiones, denominada comúnmente como de gran formato (Calvo:2002: 84-85). Existen múltiples ejemplos y pueden citarse como tales las pinturas murales del salón de Comisiones del Palacio de la Diputación Provincial de Ciudad Real (óleo sobre lienzo adherido a techo), de Ángel Andrade.

La razón de la amplia demanda de pinturas de carácter decorativo estaba junstificada por la existencia de una clase media influyente y deseosa de asistir a todo tipo de actos sociales y culturales, entre los que destacaban las respresentaciones teatrales. En el caso de España, esta circunstancia coincidió con la importante renovación que los teatros experimentaron a lo largo del siglo XIX. Las casas o corrales de comedias que tuvieron su época de esplendor durante los siglos XVI y XVII, en general, habían llegado al siglo XIX con importantes signos de degradación, lo que planteó la necesidad de su renovación o de abordar la construcción de otros nuevos que permitieran la representación de las obras de teatro apoyándose en escenografías más novedosas. Todo ello propició la construcción de numerosos teatros. Algunos ejemplos importantes son el teatro Real (1850) y el teatro Lara (1879), ambos en Madrid, el Gran teatro del Liceo de Barcelona (1847), el teatro Arriaga de Bilbao (1890), el teatro Calderón de Valladolid (1864), el teatro Romea de Murcia (1862) y el teatro Vicó de Jumilla (1883). Puesto que una de las salas más importantes de un teatro es el propio salón de actos en el que se va a llevar a cabo la representación, es lógico que el techo fuera ricamente decorado a base de molduras, lámparas y otro tipo de elementos ornamentales, entre los que destacan las pinturas de grandes dimensiones que cubren gran parte de ese espacio.

En estos entornos, los temples a la cola sobre lienzo se emplearon frecuentemente como pinturas decorativas en paredes y techos. Estas pinturas al temple en general son obras con carácter más estable, menos efímero que el que presentan otros temples, como los ejecutados en los teatros para ser utilizados como telones y pintura de escenografías en general, que tenían una mayor movilidad, debido a su uso y, por tanto, se deterioraban con mayor rapidez.

Tanto la pintura de carácter decorativo relacionada con la construcción de estos grandes edificios de carácter público, como la vinculada al arte escénico tuvieron gran demanda y su realización llegó a ser considerado un verdadero oficio, altamente valorado durante la segunda mitad del siglo XIX (García 2013: 313-359). Prueba de la importancia del arte escénico es su introducción en los programas formativos asociados a la educación de los pintores de ese siglo, llegando incluso a constituir una especialización (Catalán 2003: 113).

Las pinturas de escenografías presentaban formatos de grandes dimensiones, lo que obligaba a que fueran ejecutadas en amplísimos talleres $y$, en algunos casos, se pintaran extendidas en el suelo, de modo que el propio pintor se desplazaba sobre su superficie durante su realización (Arola 1920: 42-43; Moynet 1999: 119-120). Estos talleres podían estar integrados en los llamados almacenes de decoraciones que, en ocasiones, estaban ubicados en el propio teatro.

La pintura del techo del patio de butacas del teatro Vicó de la ciudad de Jumilla en Murcia (España) constituye un ejemplo de este tipo de obras. Este teatro fue inaugurado el 14 de agosto de 1883 y en su construcción intervinieron los arquitectos Juan J. Belmonte, que realizó los planos de la cimentación, y Justo Millán Espinosa, que diseñó los correspondientes al levantamiento del edificio. El 8 de septiembre de 1890, fue bautizado como "Teatro Vicó", en honor al actor y empresario Antonio Vicó Pintos.

Esta pintura, junto a otras decoraciones del teatro, fue encargada al pintor catalán Manuel Sanmiguel, que inició su actividad en la provincia de Murcia a partir de 1868. Sanmiguel se formó en el taller del pintor francés Felix Cagé, que llegó a ser Director de Pintura del Teatro del Liceo de Barcelona y autor de muchas de las pinturas que lo decoran (Radigales i Babi 1998: 114); además, pintó numerosas obras del Teatro Romea de Murcia (Muñoz 2018: 311-314). Respecto a la obra que nos ocupa, en el Libro de Actas 
Capitulares de los años 1883 a 1885, tomo 21, fols. 34 v. a 36 v se indica que, en la sesión de 9 de abril de 1883, y bajo la presidencia de D. Rafael Soriano Palencia, el Ayuntamiento de Jumilla (Murcia) contrata con el escenógrafo Sanmiguel la pintura del techo y decoraciones de su teatro Vico (Aragoneses, 1964). En este contrato se indica lo siguiente:

[...] Dicho señor se compromete con el Ayuntamiento, a pintar con arreglo al arte, el cielo raso sobre lienzo para colocarlo en el teatro de esta villa, [...] telón de boca y embocadura del escenario y las decoraciones siguientes: Dos decoraciones cerradas, una de carácter rico y otra de carácter medio del día, una de plaza o calle, otra de selva larga, otra de jardín, otra de cárcel, una de salón regio, una de sala corta, otra de Casa Blanca, y una de marina. Total diez decoraciones con sus correspondientes telones [...] el Ayuntamiento se compromete a entregar ó pagar a D. Manuel Sanmiguel, la cantidad de cincuenta y cinco mil reales siendo también de cuenta del Municipio, el importe del lienzo necesario para dichos decorados y la madera necesaria y construcción de ella para los bastidores y pago de los portes de todo ello desde Murcia a esta villa.

Respecto al lugar de ejecución de la pintura, es posible que Manuel Sanmiguel la realizara en el propio edificio del teatro, evitando de esta manera gastos en alquiler de espacios y desplazamiento. Esta suposición se apoya en un documento de 1889 que hace referencia al Teatro Romea de Murcia, y en el que se menciona a Sanmiguel realizando la pintura del telón de boca que tenía encargada para éste y pidiendo permiso para pintar otras obras en ese mismo lugar. Según figura en dicho documento, si le fuera concedida esta gracia, el autor correspondería pintando de manera gratuita nuevas decoraciones o restaurando otras, siempre y cuando se le suministrara el material para ello (Aragoneses, 1964). Por tanto, no puede descartarse que actuara de manera similar en el Teatro Vicó de Jumilla.

Representa una alegoría de la Música, de acuerdo al gusto de la época por el mundo clásico [Figura 1]. En la escena central, entre nubes, aparece la musa Eutherpe rodeada por siete figuras femeninas que portan distintos instrumentos musicales. En torno a ellas, se disponen tres amorcillos. Alrededor de esta escena central, se encuentran otras dos figuras femeninas que representan las alegorías de la Tragedia y la Comedia, Melpómene y Talía, además de los retratos de varias actrices (Matilde Díez, Rita Luna y Teodora Lamadrid) y dramaturgos (Calderón de la Barca, Fernández Caballero y Ricardo Calvo y José Echegaray); entre estas imágenes aparecen representadas hornacinas. En la parte inferior se hallan los retratos de los actores Julián Romea e Isidoro Maiquez. Enmarcando el conjunto de las representaciones indicadas, se encuentran una serie de figuras femeninas, que portan guirnaldas y se disponen alternativamente con una serie de cartelas en las que aparecen escritos los títulos de diferentes obras literarias y nombres de escritores. La pintura ha sido realizada para ser observada a cierta distancia, con ásperas transiciones de luces y sombras, tal y como se puede apreciar en el detalle de la figura $1 c$.

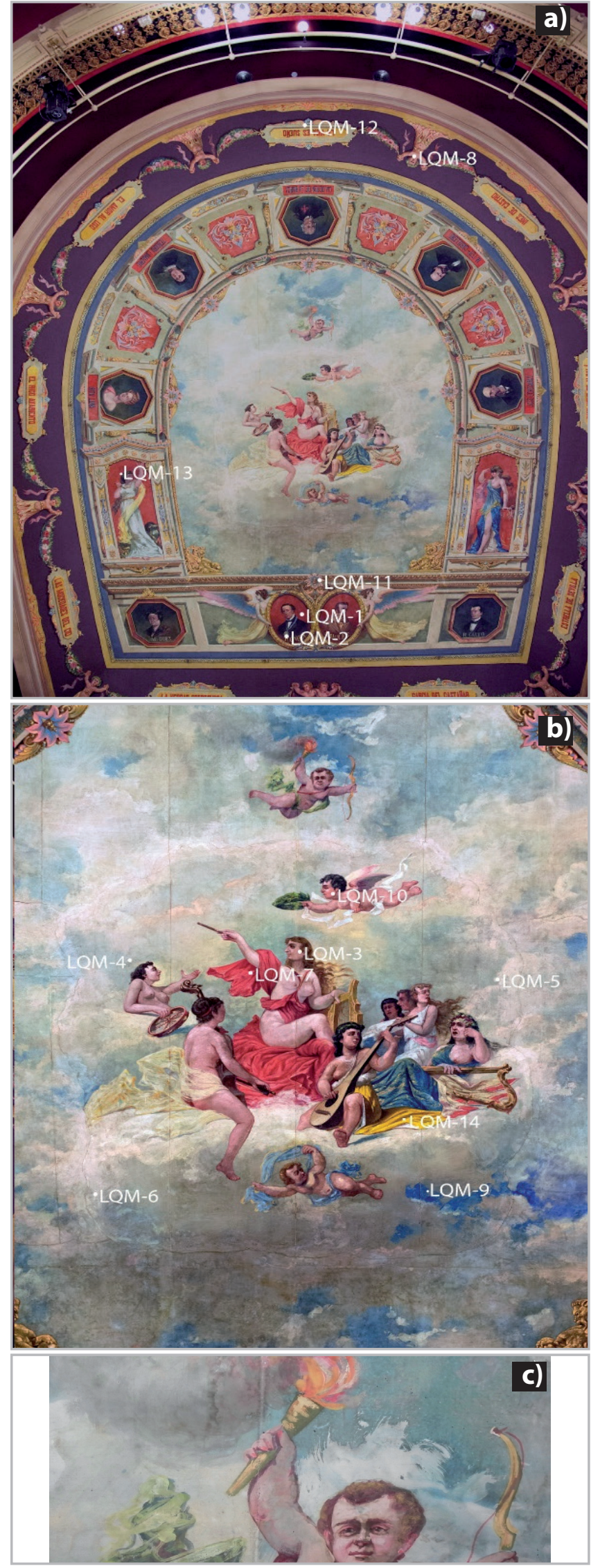

Figura 1.- a) Vista general de la pintura que decora el techo del patio de butacas del teatro Vicó de Jumilla (Murcia), b) Motivo central de la pintura. Autor de la pintura M. Sanmiguel (ca. 1884). En ambas imágenes se indican las zonas de toma de muestra. c) Detalle de uno de los amorcillos (Eros). 
La obra se inscribe en un rectángulo de 10,52 x 9,45m, Según se observa en la figura 2 , está configurada mediante la unión de diversos fragmentos de lienzo. Las líneas continuas indican que se trata de trozos de tela independientes, y las discontinuas representan costuras a punto de sábana que unen los fragmentos. El lienzo está adherido directamente al techo, sin bastidor, y el adhesivo utilizado se encuentra distribuido en toda la superficie del reverso.

Probablemente la naturaleza de los morteros y la estructura arquitectónica subyacentes hayan influido sobre el estado de conservación de la obra, aunque por el momento no se dispone de datos sobre la naturaleza de estos elementos.

Según Hilaire Hiller, este tipo de pintura sobre lienzo adherida al muro (no especifica si se trata de temple $u$ óleo) era normalmente encolada con una pasta de harina y ajo o también posteriormente con blanco de plomo con aceite. Después, el lienzo sería presionado con rodillos, desde el centro hacia los extremos a fin de conseguir una buena adherencia. (Hiler 1970: 157-158).

Dentro del proyecto integral de conservación y restauración del teatro Vicó, iniciado en mayo de 2008, fue abordada la restauración de esta pintura (De La Hoz, 2011) y en este contexto fueron llevados a cabo los análisis con el objetivo de realizar un estudio detallado de los materiales utilizados en su ejecución y su forma de aplicación. Las técnicas de análisis utilizadas y la interpretación de los resultados obtenidos, apoyadas en la consulta de documentación de la época sobre la metodología de trabajo más habitual empleada sobre este tipo de obras han hecho posible determinar la estratificación de la pintura e identificar los pigmentos utilizados, algunos de los cuales se encuentran dentro de los desarrollados por la industria química del siglo XIX. Asimismo, los resultados presentados en este artículo han ampliado el conocimiento de la técnica de trabajo aplicada en la ejecución de las pinturas al temple de cola sobre lienzo de carácter decorativo en la España del siglo XIX.

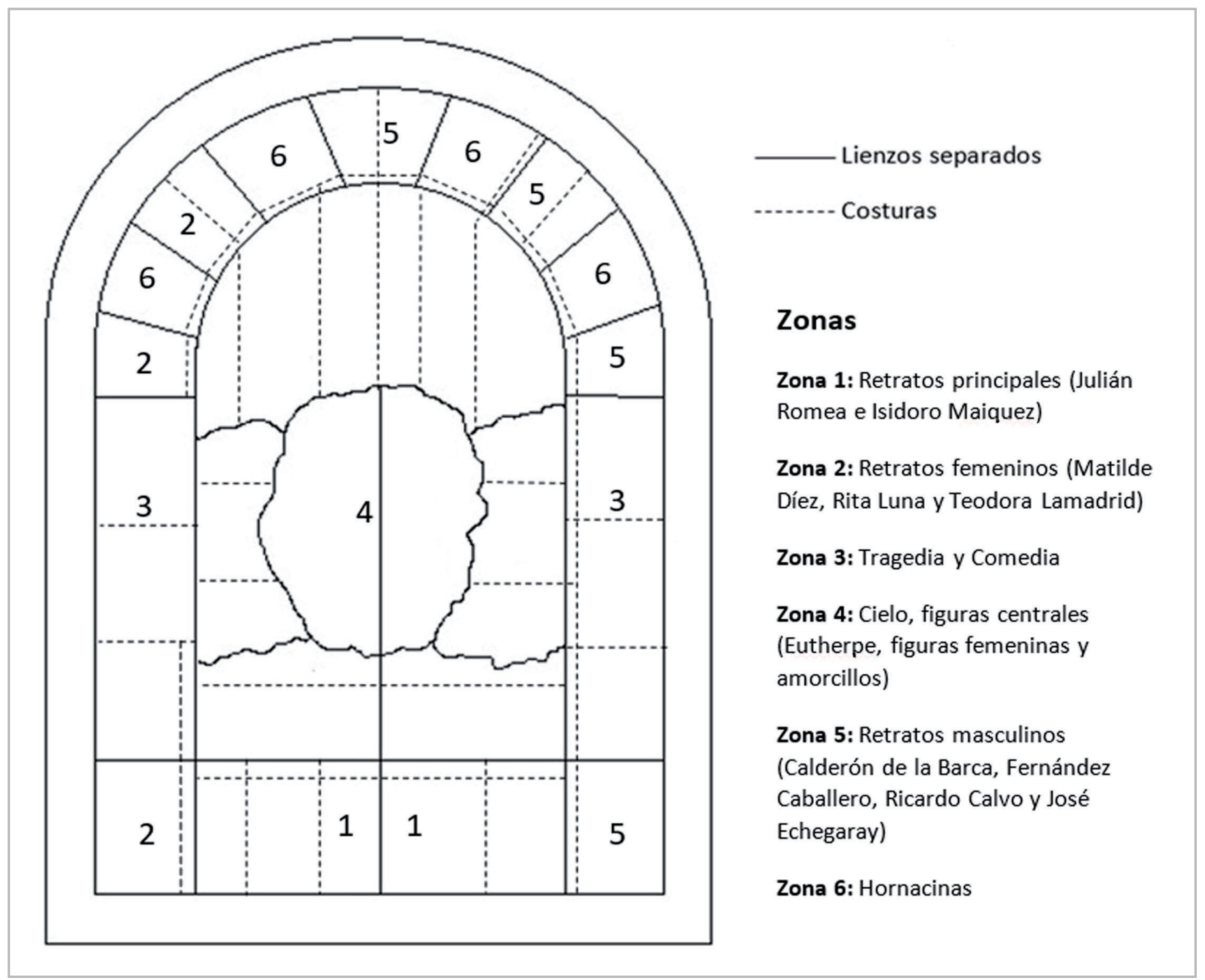

Figura 2.- Disposición de los distintos paños que constituyen la pintura. Las líneas contínuas marcan la separación entre lienzos independientes; las discontínuas indican las costuras de unión de los paños que consituyen el lienzo de la escena central. 


\section{Materiales y Métodos de análisis}

\section{-Muestras}

Se han estudiado un total de catorce muestras, que incluyen doce de pintura, una del soporte (lienzo) y otra del adhesivo de unión del soporte al techo. Dentro del conjunto de muestras pictóricas, tres de ellas corresponden a zonas repintadas. En la Tabla 1 se indica la relación de muestras, su ubicación en la obra y la referencia asignada. Las zonas en las que han sido tomadas las muestras correspondientes a la capa pictórica están indicadas en la figura 1.

Tabla 1.- Muestras estudiadas (referencia y zona de toma de muestra) ${ }^{*}, * *$

\begin{tabular}{|l|l|l|}
\hline Muestra & Referencia & Ubicación en el cuadro la pintura \\
\hline 1 & LQM-1 & Rojo fondo retrato de Julián Romea \\
\hline 2 & LQM-2 & Azul chaqueta Julián Romea \\
\hline 3 & LQM-3 & Encarnación (repinte) cara figura Eutherpe \\
\hline 4 & LQM-4 & Azul-verdoso, zona de cielo escena central \\
\hline 5 & LQM-5 & Adhesivo de unión de los lienzos al techo \\
\hline 6 & LQM-6 & Soporte (tela) \\
\hline 7 & LQM-7 & Rojo manto figura Eutherpe \\
\hline 8 & LQM-8 & $\begin{array}{l}\text { Encarnación (testigo de limpieza), figura } \\
\text { portando guirnalda (parte superior de la pintura) }\end{array}$ \\
\hline 9 & LQM-9 & Azul cielo (repinte), escena central \\
\hline 10 & LQM-10 & $\begin{array}{l}\text { Encarnación cara, figura amorcillo portando } \\
\text { corona }\end{array}$ \\
\hline 11 & LQM-11 & $\begin{array}{l}\text { Marrón (preparación?), representación moldura } \\
\text { (parte inferior de la pintura) }\end{array}$ \\
\hline 12 & LQM-12 & Rojo cartela (repinte, zona superior de la pintura) \\
\hline 13 & LQM-13 & $\begin{array}{l}\text { Verde testigo de limpieza, cabeza figura de } \\
\text { Melpómene }\end{array}$ \\
\hline 14 & LQM-14 & \begin{tabular}{l} 
Paño amarillo, figura femenina portando laúd \\
\hline
\end{tabular} \\
\hline
\end{tabular}

* Todas las muestras fueron proporcionadas por la empresa Lorquimur.

**No es posible completar los datos respecto al muro (si se trata de una estructura encamonada, cañizo, o mixta), ni de sí los morteros subyacentes que reciben el encolado, aunque sea muy interesante para la futura conservación de esta pintura ya que los autores del estudio no han tenido un acceso a la obra de esta naturaleza.

\section{—Métodos de análisis}

Las fibras han sido identificadas mediante microscopia óptica, observando la morfología de su plano longitudinal previa tinción con reactivo Herzberg (mezcla de disoluciones de cloruro de cinc y yoduro potásico/yodo).

Las muestras de pintura han sido observadas primeramente con un microscopio esteresoscopico modelo Leica MZ125 con iluminador de luz fluorescente y cámara digital Leica DC150. Después, han sido incluidas en resina acrílica polimerizable Résine Mécaprex KM-U, para su estudio por técnicas microscópicas. El estudio mediante microscopía óptica (MO) ha sido llevado a cabo con un microscopio petrográfico Olympus BX51 y el análisis morfológico y elemental ha sido realizado mediante SEM(BSE)-EDX con el empleo de un microscopio electrónico de barrido JEOL JSM 6400 que presenta 20 kV de voltaje de aceleración. Este equipo incorpora un espectrómetro de dispersión de energía LINK eXL con una resolución de 138 eV a 5.39 keV.

El análisis de los materiales organicos, es decir, del aglutinante de las capas de pintura y del adhesivo de fijación de las telas al techo ha sido realizado mediante técnicas de tinción específica, utilizando Fuchsina ácida y rectivo de Lugol, que se prepara disolviendo $20 \mathrm{~g}$ de yoduro potásico en $100 \mathrm{~mL}$ de agua y añadiendo a esta disolución $10 \mathrm{~g}$ de yodo. Además, en el caso del primero también se ha empleado croamatografía de gases-espectrometría de masas (GC-MS), utilizando un equipo GCMS-QP5050, marca SHIMADZU).

\section{Resultados y discusión}

En las muestras referenciadas como LQM-1 (rojo fondo retrato de Julián Romea), LQM-2 (azul chaqueta Julián Romea), LQM7 (rojo manto figura Eutherpe), LQM-8 (encarnación de figura portando guirnalda en la parte superior de la pintura) y LQM14 (paño amarillo, figura femenina portando laúd), se observa que la pintura parece haber sido aplicada directamente sobre el lienzo e impregna totalmente el tejido. Los estratos pictóricos presentan grosores irregulares, característica que tiene relación con la morfología ondulada de la superficie del soporte, producida por el entrecruzamiento de la trama y la urdimbre. El análisis de las fibras ha constatado que, en ambos casos, se trata de algodón [Figura 3].
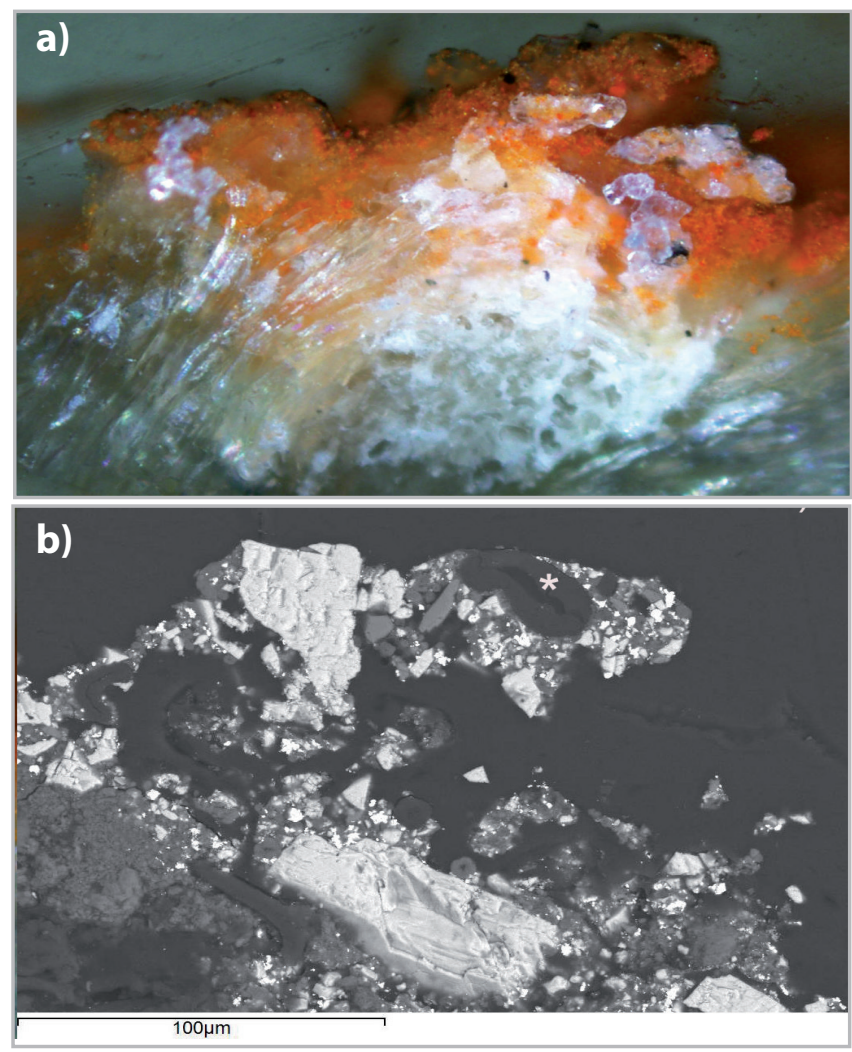

Figura 3.- Muestra LQM-1. Corte transversal: a) Observación por MO (100X); b) Observación por SEM(BSE): detalle de la capa pictórica en la que se aprecia la forma arriñonada del la seccion transversal de una fibra de algodón (señalada con un asterisco) embebida en la pintura. 
En solo cuatro de las muetras estudiadas resulta muy evidente la existencia de una capa de preparación de color blanco. Tres corresponden a zonas claras: LQM-4 (cielo), LQM-10 (encarnación) y LQM-3 (repinte de una encarnación) y la cuarta (LQM-9) corresponde a una zona más oscura del cielo. En el resto de las muestras no se aprecia claramente una capa de preparación y parece que la pintura haya sido aplicada directamente sobre el lienzo.

Esta singularidad lleva a pensar que en las zonas más relevantes de la pintura, donde se habría pretendido conseguir una pintura más luminosa se consideró oportuno aplicar una preparación de color blanco. Con esta capa previa, la pincelada discurre con mayor fluidez y, además, se limita la absorción de la capa pictórica por parte del soporte. De esta manera, se reduce además el influjo del color del lienzo en la visualización de la pintura.

Los estudios realizados por $\mathrm{MO}$ constatan que, en el caso de las muestras LQM-4, LQM-9 y LQM-10, la capa de preparación es una mezcla que contiene, además de partículas blancas, otras de color rojo-anaranjado y negro [Fig.4]. Las observaciones de las muestras en SEM (BSE), así como los análisis elementales realizados por EDX indican la presencia de calcio (Ca) como elemento mayoritario, destacándose la presencia de microfósiles y, además, otros elementos como son plomo $(\mathrm{Pb})$, en las partículas de color naranja, y fósforo (P) y calcio (Ca) en algunas de color negro, así como carbono (C) en otras que también presentan este color. [Figuras 4 y5]

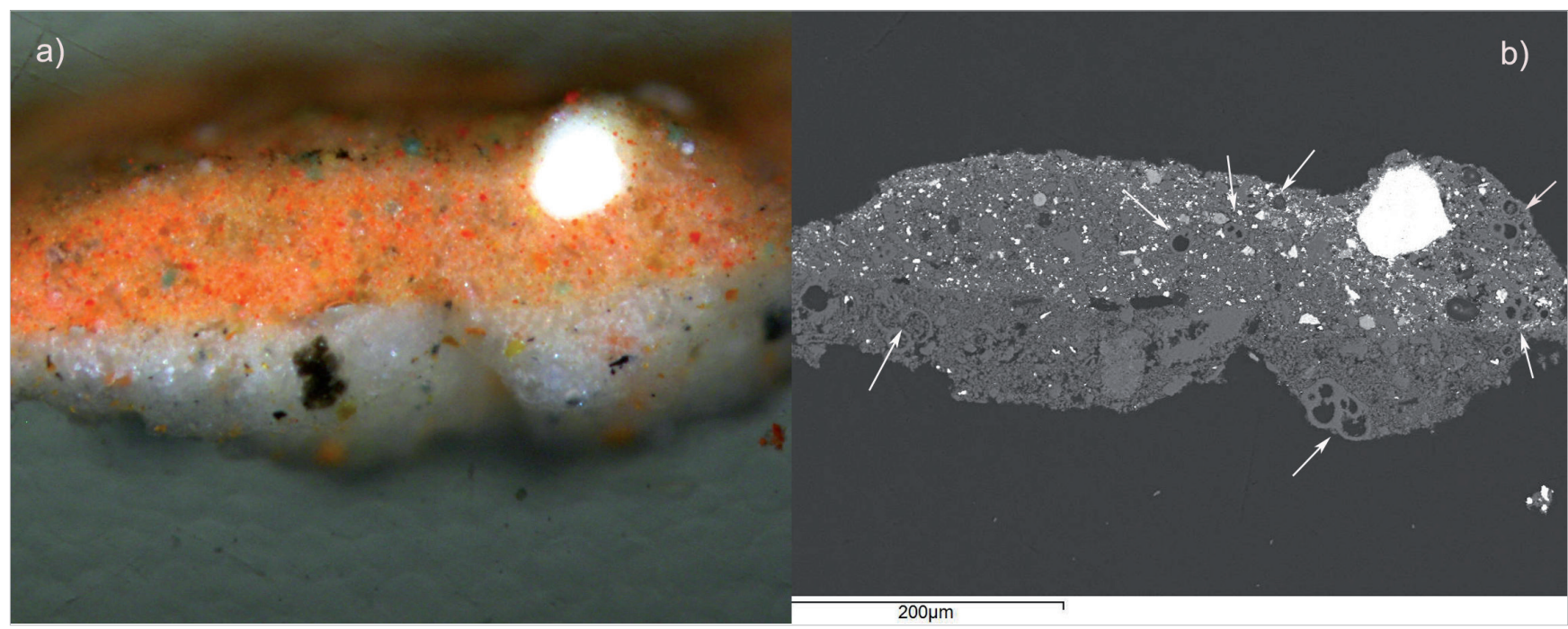

Figura 4.- Muestra LQM- 10. Corte transversal: a) Observación por MO (100X); b) Observación por SEM (BSE). Las flechas señalan la presencia de microfósiles.

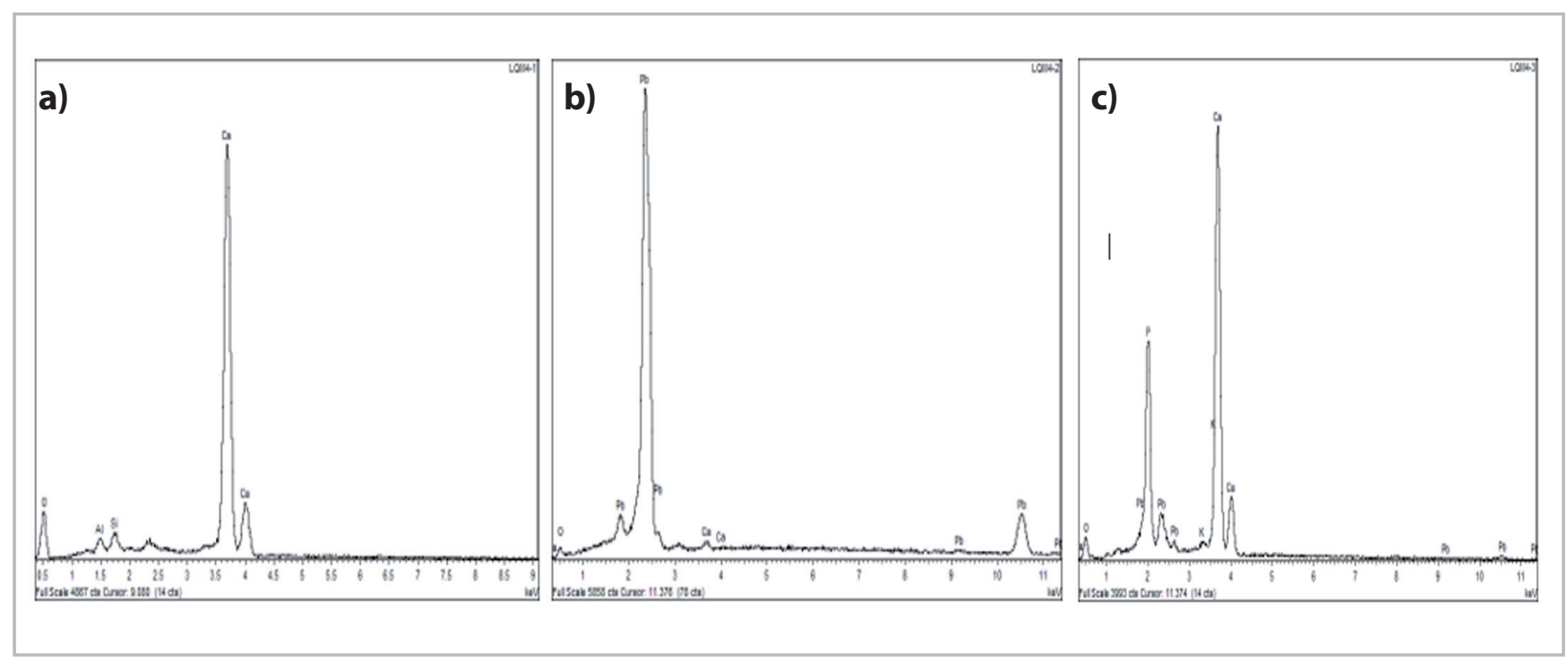

Figura 5.- Muestra LQM-10. Microanálisis por EDX correspndientes a la capa de preparación: a) análisis de zona; b) análisis de partículas de color naranja; c) análisis de partículas negras. 
Atendiendo a estos resultados, la composición de la capa de preparación en las muestras que la presenta es carbonato cálcico de origen orgánico (creta), mezclada con un pigmento de plomo, probablemente minio y dos tipos de pigmento negro, negro carbón y negro de huesos.

En la muestra LQM-3, que corresponde a una zona donde visulamente fue identificado un repinte de acuerdo a las indicaciones de Lorquimur, la empresa que suministró las muestras para su análisis, se ha observado una capa de preparación constituida únicamente por carbonato cálcico. En ella no se observan microfósiles, como ocurría en el caso de la capa de preparación de las muestras correspondientes a la capa pictórica original, lo que contribuiría a diferenciar las preparaciones [Figura 6]. Este repinte, al igual que el que correponde a la zona de extracción de la muestra referenciada como LQM-12 (rojo cartela, repinte), podría tener su origen en alguna intervención anterior destinada a adecentar la decoración en algún momento de la historia de la obra.

La técnica pictórica frecuentemente asociada a este tipo de pintura es el temple a la cola, que se caracteriza por su rigidez. Esta peculiaridad, unida a las grandes dimensiones de estas obras y a la manipulación a la que se veían sometidas durante su ejecución, transporte y colocación en su ubicación definitiva, podía dar lugar a pérdidas de pintura si las capas eran muy gruesas y no impregnaban convenientemente el soporte.

En el caso de la pintura objeto de estudio, se observa esa penetración en el soporte y la delgadez de la pintura e, incluso, la ausencia de preparación en la mayoría de las muestras estudiadas durante los exámenes microscópicos.

El uso del carbonato cálcico en la capa de preparación puede tener relación con la existencia de numerosos tratados foráneos en los que se menciona este material y el frecuente trasiego de artífices por la Europa del siglo XIX. A este respecto recuérdese el origen francés de la propia formación artística de Sanmiguel. Estas circunstancias, sin duda, pudieron favorecer ese "contagio" de materiales y metodologías pictóricas (Bellanger 1899: 230-231) [1].

De la transmisión entre países de metodologías pictóricas y uso de materiales dan fe algunos textos, como el titulado Técnica del arte de la pintura o Libro de la pintura (1959), de José Manaut Viglieti, que describe en detalle el proceso de preparación de los temples sobre lienzo. Dentro de sus indicaciones, este autor señala la posibilidad de utilizar tierra blanca (carbonato cálcico?), en lugar de yeso, posiblemente por ese intercambio de conocimientos con otros países (Manaut 1959: 161-162).

Como se ha indicado, algunos tratados se refieren a ese empleo de carbonato cálcico en preparaciones y como pigmento en pintura al temple sobre lienzo, Pueden citarse, por ejemplo, el de Du Puy Du Grez, Traité sur la peinture pour en apprendre la theorie \& le perfectionner dans la pratique (1699) (Du Puy 1700: 239), el de AntoineJoseph Pernety, titulado Dictionnaire protatif de peinture, sculpture et gravure (1757), (Pernety 1757: xxx. xxii-xxxvi) o el de Watin, en $L^{\prime}$ art du Peinture, Doreur, Vernisseur (1772) (Watin 1793: 109). Igualmente, existen textos del siglo XIX y posteriores en los que se menciona el uso del carbonato cálcico (Vernon-Smith 2013). Su uso como pigmento en una técnica como es el temple a la cola se fundamenta en que este aglutinante mantiene el poder cubriente del carbonato.

Por otra parte, en cuanto a la presencia de carbonato cálcido en la capa pictórica de algunas de las muestras estudiadas, no debe descartarse la posibilidad de que haya sido utilizado como carga de pigmentos más costosos, como el blanco de plomo. Es bien conocido que este último era comercializado con diversas calidades y

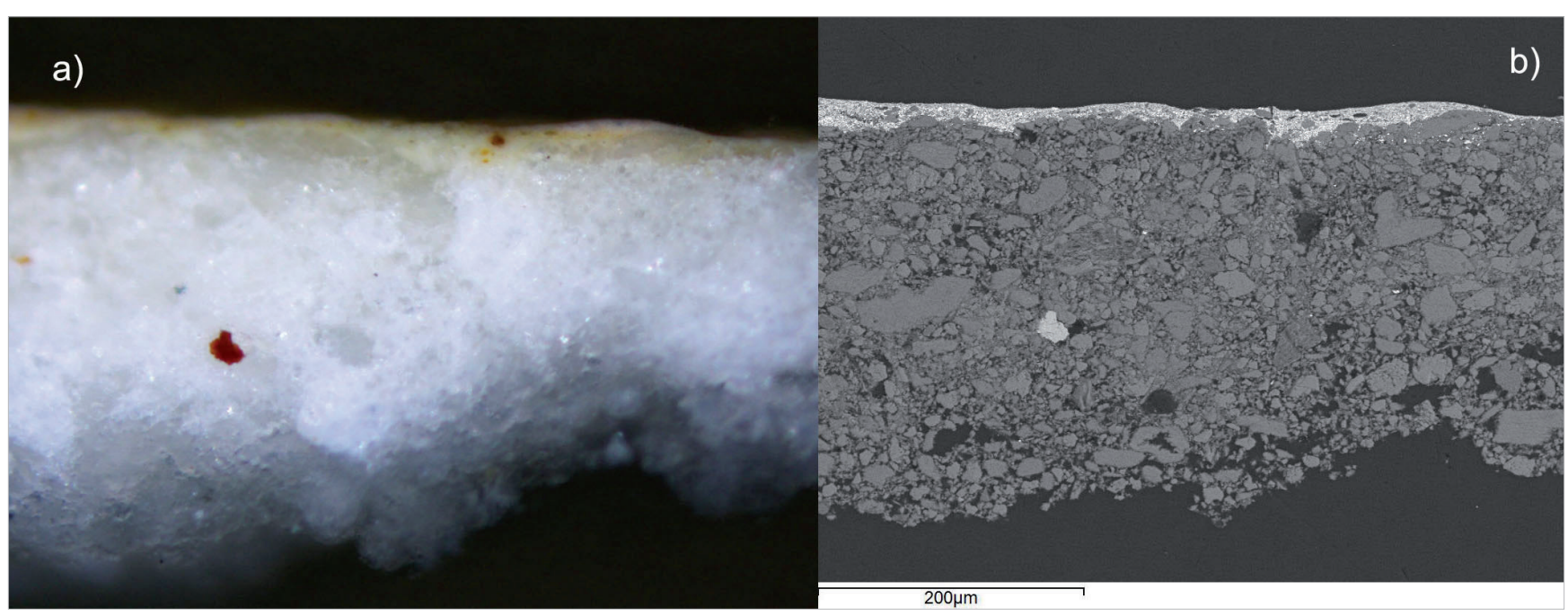

Figura 6.- Muestra LQM- 3. Corte transversal: a) Observación por MO (100X); b) Observación por SEM (BSE). 
precios. En la versión más económica de este pigmento, el carbonato cálcico figuraba como carga. Hay que indicar que, además de este carbonato, también ha sido identificada la presencia de yeso en la capa pictórica de algunas muestras; este es el caso de LQM-10, LQM-13 y LQM-14, de lo que se deduce que este último material también pudo haber sido utilizado como carga.

Con repsecto a la capa pictórica, lo primero que hay que indicar es la amplia gama de colores utilizada (blanco, amarillo, azul, verde, rojo, naranja, negro), obtenidos todos ellos por mezcla de pigmentos y aplicados en general en una única capa. En la Tabla 2 se recogen los resultados de los microanálisis realizados por EDX sobre los distintos pigmentos y cargas presentes en la pintura. Dentro de éstos, algunos son tradicionales, y tienen una amplia trayectoria de uso en pintura artística y otros son más modernos, estando en algunos casos su fecha de producción y comercialización dentro de la primera mitad del sigo XIX.

Se han identificado pigmentos tradicionales como son blanco de plomo, bermellón, minio, negro de huesos, negro carbón y tierras (San Andrés, Sancho, de la Roja 2010) y, además, carbonato cálcico y yeso, a los que ya se ha hecho referencia anteriormente. Tambien se han detectado otros pigmentos más modernos cuya producción y comercialización están estrechamente relacionadas con el nacimiento de la Química moderna (San Andrés 2010). En orden cronológico, el primero que hay que mencionar es el azul de Prusia, ferrocianuro férrico, cuya fecha de síntesis se sitúa entre 1704 y 1706, y es debida a Diesbach y Dippel. Fue comercializado poco después, en 1708 y fue inmediatamente aceptado en pintura artística (Berrie 1997). Otro de los pigmentos identificados es el amarillo Turner, también conocido como Patent Yellow, oxicloruro de plomo, sintetizado por el químico y farmacéutico británico Carl Wilhelm Scheele en 1770. Este producto de color amarillo, Ilama la atención del industrial Turner, a quien debe su nombre y que en 1781 patenta su procedimiento de obtención (Russell 2000: 165). Es mencionado por el fabricante de colores George Fields que indica que puede ser utilizado en la técnica al óleo y al temple, pero advierte que se puede alterar bajo la acción de la luz y de la contaminación (Fields, 1841: 144) razón por la cual, su uso queda relegado a pintura decorativa. En relación a esta recomendación, es posible que esta sea la razón de las escasas referencias que existen a la identificación de este pigmento en pintura artística (Pisareva, 2005).

El blanco de bario, químicamente es un sulfato de bario, que puede ser de origen natural o sintético. El primero procede de la barita, mineral de la misma composión del pigmento, y su uso se remonta a la antigüedad. Pero es a raíz de su obtenión com producto sintético, cuando se intensifica su empleo como pigmento. El descubrimiento de su método de obtención se situa a finales del sglo XVIII y principios del XIX (Eastaugh, Walsh, Chaplin, Siddall 2004: 40-41).

Otro pigmento amarillo que ha sido identificado es el amarillo de cromo,), cuya síntesis está relacionada con el descubrimiento del cromo) como elemento químico y el estudio de sus propiedades y derivados. El cromato de plomo(II) fue obtenido en torno a 1800, y en 1804 los químicos franceses Berthollet y Vauquelin sugieren su uso como pigmento. Hay que esperar a 1816 año en el que el fabricante de pigmentos inglés Bollman inicia su producción, pero no es hasta 1831 cuando el industrial Andreas Kurtz de Manchester logra su introducción en el mercado (Russell 2000:164).

El pigmento verde identificado es un pigmento de cobre (Cu) y arsénico (As) de origen sintético. Podria tratarse de Verde Schweinfurt, acetato arsenito de cobre (II) o bien del verde Scheele. Respecto al primero, también conocido como verde de Paris y verde esmeralda, fueron varios los protagonistas responsables de su síntesis y comercialización. Uno de ellos fue Wilhelm Sattler, fabricante de pinturas de Schweinfurt (Alemania), que en colaboración con el farmacéutico Friedrich Russ lo comercializa en 1814 bajo el nombre de verde Schweinfurt. Otra posibilidad es que se trate del verde Scheele. pigmento sintetizado en 1775, por Scheele y que responde a la composición del arsenito de cobre(II).

Tabla 2.-Pigmentos y cargas identificados. Resultados microanálisis EDX.

\begin{tabular}{|c|c|c|}
\hline Pigmento & $\begin{array}{l}\text { Análisis } \\
\text { elemental } \\
\text { (SEM - EDX) }\end{array}$ & Formula química \\
\hline $\begin{array}{l}\text { Amarillo de } \\
\text { Cromo }\end{array}$ & $\mathrm{Cr}, \mathrm{Pb}$ & $\left(\mathrm{PbCrO}_{4}\right)$ \\
\hline $\begin{array}{l}\text { Amarillo de } \\
\text { Turner }\end{array}$ & $\mathrm{Cl}, \mathrm{Pb}$ & $\left(\mathrm{PbCl}_{2.5-7} \mathrm{PbO}\right)$ \\
\hline Azul de Prusia & $\mathrm{Fe}$ & $\mathrm{Fe}_{4}\left[\mathrm{Fe}(\mathrm{CN})_{6}\right]_{3}$ \\
\hline $\begin{array}{l}\text { Blanco de } \\
\text { bario }\end{array}$ & $\mathrm{S}, \mathrm{Ba}$ & $\mathrm{BaSO}_{4}$ \\
\hline Bermellón & $\mathrm{S}, \mathrm{Hg}$ & $\mathrm{HgS}$ \\
\hline $\begin{array}{l}\text { Blanco } \\
\text { de plomo } \\
\text { (albayalde) }\end{array}$ & $\mathrm{Pb}$ & {$\left[\mathrm{Pb}_{3}\left(\mathrm{CO}_{3}\right)_{2}(\mathrm{OH})_{2}\right]$} \\
\hline $\begin{array}{l}\text { Carbonato } \\
\text { cálcico }\end{array}$ & $\mathrm{Ca}$ & $\mathrm{CaCO}_{3}$ \\
\hline Minio & $\mathrm{Pb}$ & $\mathrm{Pb}_{3} \mathrm{O}_{4}$ \\
\hline $\begin{array}{l}\text { Negro de } \\
\text { huesos }\end{array}$ & $\mathrm{Ca}, \mathrm{P}$ & $\mathrm{Ca}_{3}\left(\mathrm{PO}_{4}\right)_{2}$ \\
\hline Negro carbón & C & C \\
\hline Tierra & $\mathrm{Si}, \mathrm{Al}, \mathrm{Fe}, \mathrm{Mn}$ & $\mathrm{aSiO}_{2} \cdot \mathrm{bAl}_{2} \mathrm{O}_{3} \cdot \mathrm{cNa}_{2} \mathrm{O} \cdot \mathrm{dMnOx} \cdot \mathrm{eFe} \mathrm{O}_{3}$ \\
\hline $\begin{array}{l}\text { Verde } \\
\text { Schweinfurt }\end{array}$ & $\mathrm{As}, \mathrm{Cu}$ & {$\left[\mathrm{Cu}_{4}\left(\mathrm{C}_{2} \mathrm{H}_{3} \mathrm{O}_{2}\right)\left(\mathrm{AsO}_{2}\right)_{2}\right]$} \\
\hline Verde Scheel & $\mathrm{As}, \mathrm{Cu}$ & {$\left[\mathrm{Cu}\left(\mathrm{HAsO}_{3}\right)_{2}\right]$} \\
\hline Yeso & $\mathrm{Ca}, \mathrm{S}$ & $\mathrm{CaSO}_{4} \cdot 2 \mathrm{H}_{2} \mathrm{O}$ \\
\hline
\end{tabular}


Algunos de los pigmentos referidos pueden ser observados en la figura 4, correspondiente a la muestra LQM- 10. En esta última se han identificado los siguientes pigmentos: blanco de plomo, barita, minio, bermellón y verde de Schweinfurt o verde Scheel. También se han detectado algunas partículas de yeso. En la figura 7 se muestran algunos de los resultados de los microanálisis realizados sobre la capa de pintura de esta muestra.
En cuanto al estudio de los materiales orgánicos utilizados como adhesivo de fijación del lienzo al techo del teatro y de los aglutinantes de las capas pictóricas, en una primera etapa, se han utilizado técnicas de tinción específicas (reactivos Lugol y Fuchina ácida). La muestra de adhesivo (LQM-5) ha dado resultado positivo con el reacivo Lugol, adquiriendo una coloración azulviolacea característia de la presencia de almidón. Asimismo, la tinción con fuschina ácida ha resultado positiva en todas las muestras, exceptuando la capa pintórica del repinte (Figura 8).

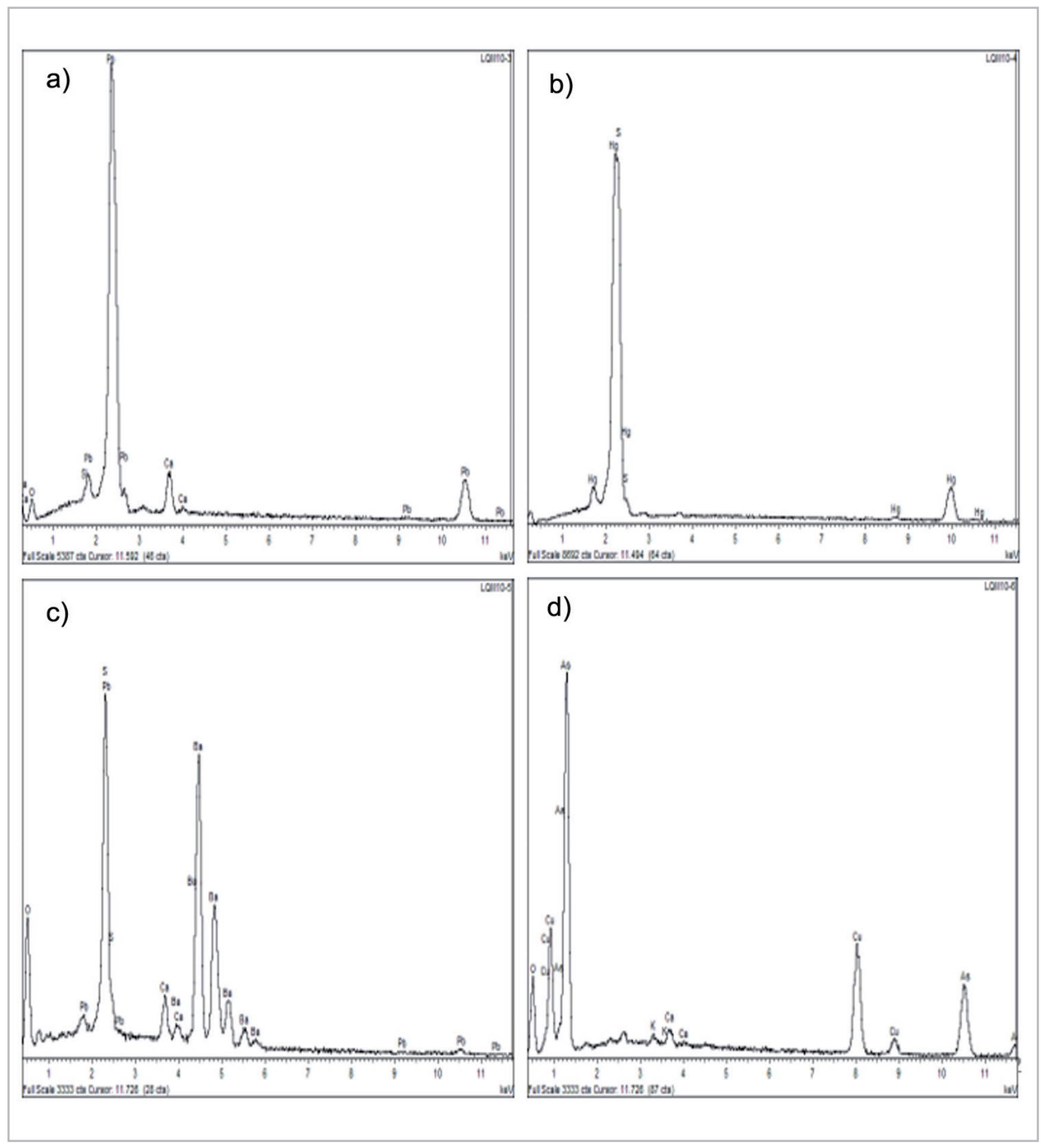

Figura 7.-Muestra LQM-10. Microanálisis por EDX correspondientes a la capa pictórica de color rojo anaranjado: a) partículas blanco de plomo; b) grano de bermellón; c) área con barita mezclada con pigmento de plomo y creta; d) verde con As y Cu. 


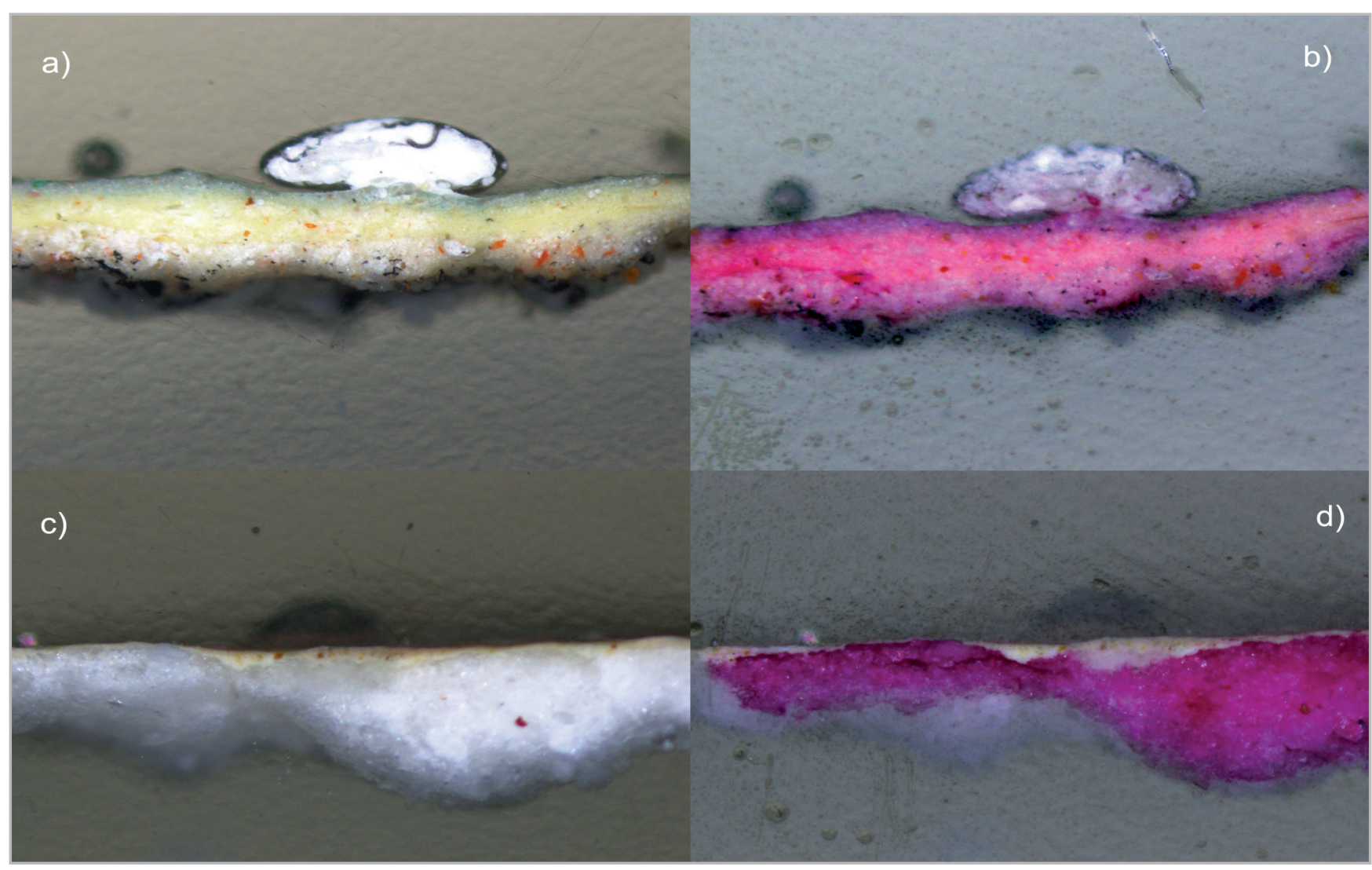

Figura 8.-Observación por MO de la muestra LQM-4 (50X): (a) antes (b) después de la tinción con fuschina ácida. Los resultados son positivos en todas las capas (preparación y capa pictórica). Muestra LQM-3 (50X) correspondiente a un repinte (c) antes y (d) después de la tinción con fuschina ácida con resultado positivo en la tinción de la capa de preparación unicamente.

Los ensayos de tinción para el estudio del aglutinante con fuschina ácida han sido positivos si se exceptúa la capa pictórica del repinte, como se puede apreciar en la Figura 8.

El resultado negativo en la tinción con fuchina de la muestra de repinte podría llevar a pensar en la presencia de un aceite secante en esta capa. Sin embargo, los análisis realizados mediante GCMS no han permitido confirmar la presencia de este tipo de aglutinante. Según se recoge en la tabla 3 y en las figuras 9 y 10.

Tabla 3.- Resultados de los análisis GC-MS

\begin{tabular}{|c|c|c|c|c|c|c|}
\hline Muestra & $n^{\circ}$ pico & $\begin{array}{c}\mathrm{t}_{4} \\
\text { (minutos) }\end{array}$ & $\mathrm{m} / \mathrm{z}$ & $\begin{array}{l}\text { Especie } \\
\text { quimica }\end{array}$ & area pico (96) & Relación P/S \\
\hline \multirow{2}{*}{ LQM-3 } & 1 & 11,902 & $74,87,143$ & $\mathbf{P}$ & 39,60 & \multirow[b]{2}{*}{0,65} \\
\hline & 6 & 14.573 & $74,87,143$ & E & 60,40 & \\
\hline \multirow{2}{*}{ LQM-9 } & 1 & 11,925 & $74,87,143$ & $\mathbf{P}$ & 40,12 & \multirow[b]{2}{*}{0,67} \\
\hline & 6 & 14.595 & $74,87,143$ & $E$ & 58,88 & \\
\hline \multirow[b]{2}{*}{ LQM-12 } & 1 & 11,911 & $74,87,143$ & P & 41,03 & \multirow[b]{2}{*}{0,69} \\
\hline & 6 & 14.581 & $74,87,143$ & $\mathrm{E}$ & 58,97 & \\
\hline
\end{tabular}

P: ácido palmítico

E: ácido esteárico

tr: tiempo de retención

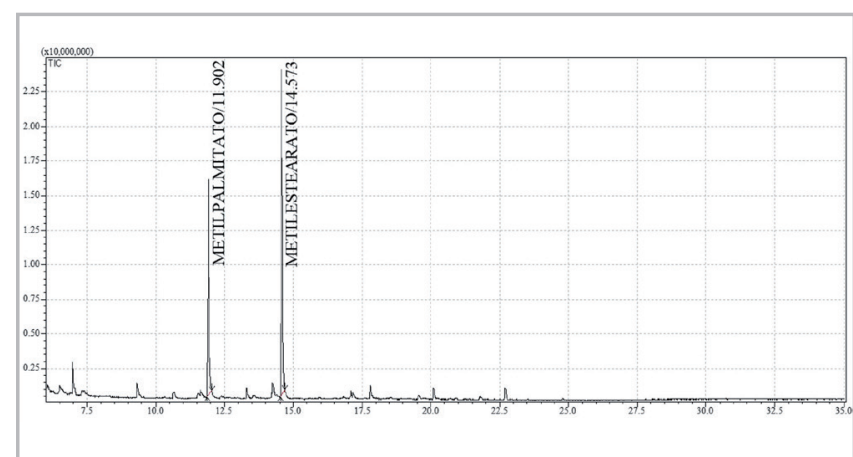

Figura 9.-Muestra LQM-3. Cromatograma correspondiente al aglutinante de la capa pictórica.

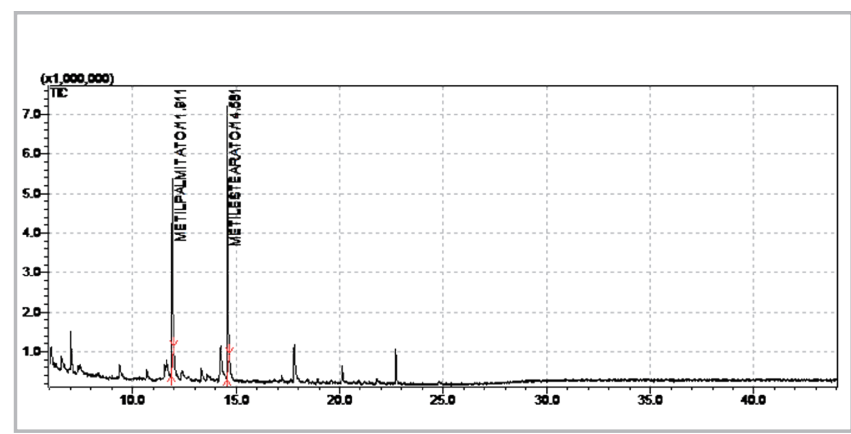

Figura 10.-Muestra LQM 12. Cromatograma correspondiente al aglutinante de la capa pictórica. 
En todos los casos, se han detectado los esteres metílicos de los acidos palmítico y esteárico, lo que nos indica la prsencia de una grasa (la cola animal contiene grasa), pero no relacionada con aceites secantes, puesto que la relación $\mathrm{P} / \mathrm{S}$ es muy inferior a la que corresponderia a una aceite secante [2]. Además, la ausencia del pico correspondiente al éster metílico del ácido azeláico, igualmente confirma que no existe un aceite secante ya que este ácido se forma durante el proceso de secado de este tipo de aceites

El cromatograma y las características de los picos identificados [Figura 10] indican que no se trata de un aceite secante.

A partir del conjunto de los resultados obtenidos, se puede interpretar que la técnica pictórica utilizada para pintar la obra es un temple. Probablemente se trate de un aglutinante protéico en el caso de la pintura original mientras que, en lo que respecta a los repintes, podría tratarse de una goma.

\section{Conclusiones}

El estudio analítico de la pintura del techo del teatro Vicó de Jumilla ha contribuido al conocimiento de los materiales y técnica de trabajo empleados en las pinturas al temple sobre lienzo del siglo XIX. Se ha constatado que en algunas zonas la capa pictórica impregna profundamente el soporte textil y que no se aprecia preparación en un gran número de muestras; de esta manera se limitarían las pérdidas de pintura, durante el proceso de ejecución y su colocación en su emplazamiento definitivo.

En las zonas en las que existe preparación ha sido identificado carbonato cálcico de origen natural (creta) como componente mayoritario. Este también también ha sido detectado en la capa pictórica. La existencia de preparación puede tener relación con la intención de dar luminosodad a la pintura y minimizar el efecto del color del soporte.

Por otra parte, se apunta hacia el empleo de cola animal como aglutinante, tanto en la capa pictórica como en la preparación, manteniendo así una técnica tradicional para este tipo de trabajos.

En la relación de pigmentos utilizados, destaca el uso de numerosos pigmentos modernos, sintetizados $y$ comercializados algunos en el siglo XVIII, como el azul de Prusia y el amarillo Turner, y otros en el siglo XIX, como el blanco de bario, amarillo de cromo y verdes de arseniato de cobre, Schweinfurt o Scheele. Con esto se desmuestra que Sanmiguel utilizó en la ejecución de esta obra pigmentos artísticos novedosos.

\section{Agradecimientos}

Esta investigación ha sido financiada por el contrato de investigación firmado con la empresa Lorquimur al amparo del Art. 83 de la L.R.U, y a quienes las autoras agradecen la información suministrada. Tambien agradecen el soporte económico del Proyecto TopHeritage-CM (S2018/NMT-43724) y el apoyo del el CNME (Centro Nacional de Microscopía Electrónica) de la Universidad Complutense de Madrid. Los análisis de cromatografía de gases-espectrometría de masas han sido realizados en el Laboratorio de Materiales del Instituto de Patrimonio Cultural del España (IPCE) con el equipo SHIMAZU QP5050A El.

\section{Notas}

[1] Por ejemplo, Camilo Bellanger, en su obra traducida del francés en 1899 Manual de pintura al alcance de todo el mundo se refiere a la mezcla de yeso y carbonato cálcico con cola de pescado en las preparaciones de los lienzos (si bien el ejemplo se refiere a la pintura al óleo).

[2] Por ejemplo en el caso del aceite de linaza: $\mathrm{P} / \mathrm{S} \sim 1,4-2,0$.

\section{Bibliografía}

ARAGONESES, J. (1964). Pintura decorativa en Murcia. Siglos XIX y $X X$. Murcia: Diputación Provincial de Murcia.

AROLA, F. (1920). Escenografía. Barcelona: Calpe.

BELLANGER, C. (1899). Manual de pintura al alcance de todo el mundo. (trad. franc. By E. Zamacois). París. Garnier Hermanos, Libreros-Editores

BERRIE, B. H. (1997). "Prussian Blue". En Artists'Pigments, A Handbook of their History and Characteristics, E.W. Fitzhug (ed.). Vol. 3. Oxford: Oxford University Press, pp.191-217.

CALVO, A. (2002). Conservación y restauración de pintura sobre lienzo, Barcelona: Ediciones del Serbal.

CATALÁN, M. S. (2003). La escenografía de los dramas románticos españoles (1834-1850). Zaragoza: Prensas Universitarias de Zaragoza. Zaragoza.

DE LA HOZ, J., CAÑADAS, P., PÉREZ, J, DE LA HOZ, L, CAÑADAS, M. (2011). "Restauración de Cubiertas y Fachadas. Teatro Vicó. Jumilla". En XXII Jornadas de Patrimonio Cultural de las Region de Murcia, Melgares, J. A., Collado, P. E., Bascuñana, J. A (coord..). Murcia. Ed. Tres Fronteras. Consejería de Cultura y Turismo, pp. 259-274.

DU PUY DU GREZ, B. (1700). Traité sur la peinture pour en apprendre la theorie \& le perfectonnerdans la pratique, (1 a ed. de 1699, París). París : Florentin et Pierre Delaulne.

EASTAUGH, N, WALSH, V, CHAPLIN, T, SIDDALL, R. (2004). Pigment Compendium. A dictionary of Historical Pigments. Oxford: Elsevier Butterworth-Heinemann. 
FIELD, G. (1841): Chromatography or a Treatise on Colours and Pigments: and of their Powers in Painting (new edition improved), Tilt and Bogue, London.

GARCÍA,M. (2013). "Oficios del pintor en el siglo XIX" en María del Carmen Lacarra (Coord.): Arte del siglo XIX, Zaragoza: Institución Fernando el Católico.

HILER, H. (1970). The Painter's Pocket-Book of Methods and Materials. London: Faber \& Faber, 1975.

MANAUT, J. (1959). Técnica del arte de la pintura o Libro de la pintura. Madrid: Dossat.

MOYNET, M. J. (1999). Elteatro pordentro; maquinariay decoraciones. ( $1^{\text {a }}$ ed. 1873 vers. esp. de Cecilio Navarro de 1885. Primera ed. facs.). Madrid: Asociación de Directores de Escena de España.

MUÑOZ, A. (2018). La conservación de bienes culturales en Murcia en el S XIX.Tesis Doctoral. Universidad de Murcia. Escuela Internacional de Doctorado. Disponible en: https://digitum. um.es/.../Amparo\%20Muñoz\%20Fernández\%20Tesis\%20 Doctoral.pdf [Consulta: 24-07-2019].

PERNETY, A. J. (1757). Dictionnaire protatif de peinture, sculpture et gravure. París: Libraire, Quai des Augustins, à SainteGenevieve, \& à S Jean dans le Désert.

PISAREVA, S. (2005). Some Occurrences of Patent Yellow, Studies in Conservation, 50, pp. 33-36.

RADIGALES Y BABI, J. (1998). Els orígens del gran teatre del Liceu (1837-1847). Barcelona: Publicacions de I’Abadia de Montserrat.

RUSSELL, C. A. (ed.) (2000). Chemistry, Society and Environment. A New History of the British Chemical Industry, England: The Royal Society of Chemistry.

SAN ANDRÉS, M., SANCHO, N., DE LA ROJA, J. M. (2010). "Alquimia. Pigmentos y Colorantes Históricos", Anales de Química, 106, pp.58-65.

SAN ANDRÉS, M. (2010). "Química Moderna y Producción de Nuevos Pigmentos". En Fatto d'Arquimia. Historia $e$ identificación de pigmentos artificiales en las técnicas pictóricas. Madrid: Secretaría General Técnica. Subdirección General de Publicaciones, Información y Documentación (Ministerio de Cultura), Madrid, pp.27-54.

SANTOS, S. (2017). "Las sargas y otros modos de temple: estudio comparativo experimental", revista ph, 92, pp. 192-209.

VERNON-SMITH, H. (2013). "The changing practice of scenic painters in England". En Setting the scene, Costaras, N, Young, (eds.). Plymouth: Archetype Publications, pp. 92-98.

WATIN, J. F. (1793). L' art du Peinture, Doreur, Vernisseur, (first ed. 1772). Quatrieme édition. París:ChezL`Auteur, rue Sainte-Apolline.

\section{Autor/es}

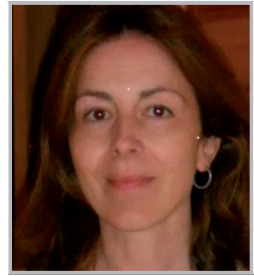

\section{Sonia Santos Gómez}

soniasantos@ucm.es

Facultad de Bellas Artes. UCM

Doctora por la Universidad Complutense de Madrid con la tesis doctoral: Las preparaciones de yeso en la pintura sobre tabla de la Escuela Española. Ha desarrollado una triple labor como docente, investigadora y profesional en el ámbito de la conservación de bienes culturales. Desarrolla su labor docente en la Facultad de Bellas Artes de la Universidad Complutense de Madrid. En el campo de la conservación-restauración, ha trabajado en diferentes instituciones, entre las que se encuentran Patrimonio nacional, obispados, ministerios y museos. Ha desarrollado su actividad investigadora a través de diferentes proyectos de investigación financiados. Fruto de todo ello son la publicación de libros, artículos y participación con ponencias en congresos: Santos, S. (2015), El yeso: Su elaboración y empleo en la pintura y dorado de retablos, Almería: Círculo Rojo; Santos, S., (2017), La Conservación del Arte Contemporáneo: Criterios y metodologías de actuación en obras configuradas con nuevos materiales, Oviedo, ed. Trea; Santos, S., San Andrés, M. (2004): "La pintura de sargas" Archivo Español de Arte, CSIC, t. LXXVII, no 305, Enero-Marzo 2004, 59-74.; Santos, S. (2019): Nuevas aportaciones sobre la temática y utilidad de la pintura de sargas, Goya, 369, pp. 294-305.

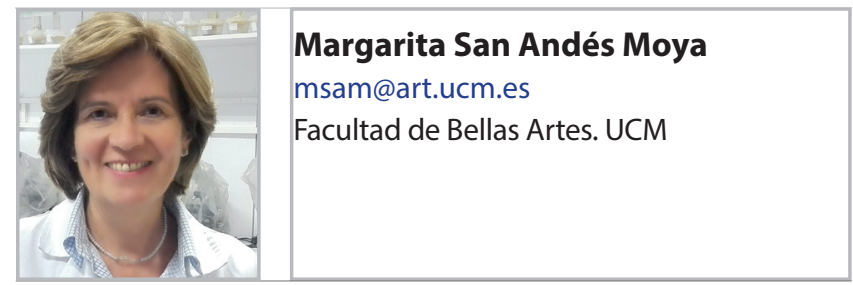

Dra. en Ciencias Químicas por la UCM y Profesora Titular (acreditada a Cátedra) del Departamento de Pintura y ConservaciónRestauración de la Facultad de Bellas Artes. Su actividad docente e investigadora se centra en la aplicación de las ciencias experimentales en el estudio material del patrimonio cultural, su conservación y restauración. Es coautora de 150 publicaciones y 5 patentes. Ha participado en 20 Proyectos de investigación, en 12 como Investigadora Principal. Es Directora del Grupo de Investigación UCM "Técnicas de Documentación, Conservación y Restauración del Patrimonio". Es Directora del Laboratorio de Materiales de la Facultad de Bellas Artes, certificado bajo norma ISO 9001:2015 e integrado en la Red de Laboratorios e Infraestructuras de la Comunidad de Madrid (Lab 397). Ha dirigido 10 Tesis Doctorales. Desde el 2011 es miembro electo representante del nodo de Universidades de la Comisión Ejecutiva de la Red de Excelencia TechnoHeritage. Ha sido Vicerrectora de Extensión Universitaria y Secretaria Académica de la Facultad de Bellas Artes de la UCM. Actualmente es Vicerrectora de Investigación y Transferencia de la UCM 


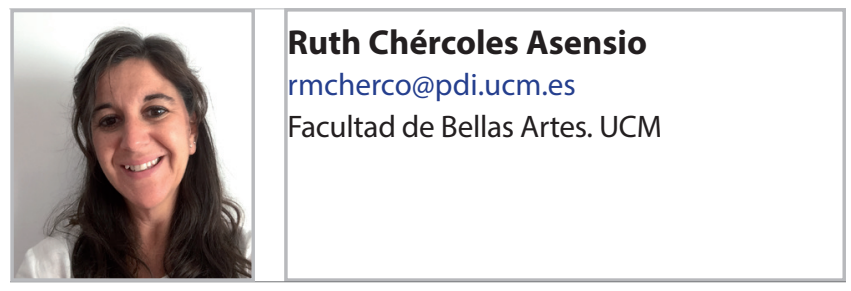

Licenciada en CC. Químicas y Doctora en Bellas Artes de la UCM, Master de Restauración y Rehabilitación de Patrimonio Histórico de la Universidad de Alcalá de Henares. Profesora en el Grado de Conservación y Restauración de la Facultad de Bellas Artes de la UCM y Responsable de Calidad del laboratorio de materiales de la Facultad de Bellas Artes de la UCM, incluido dentro de la Red de laboratorios e Infraestructuras de la Comunidad Autónoma de Madrid. Su actividad investigadora, docente y profesional está vinculada a la Conservación y Restauración del Patrimonio Cultura desde hace 13 años, especializandose en el estudio de propiedades, comportamiento y técnicas de análisis aplicadas a materiales del patrimonio cultural. Su labor investigadora en los últimos años se centra en la caracterización de polímeros utilizados en conservación y restauración y el estudio de su comportamiento físico y químico aplicando ensayos de envejecimiento artificial.

Artículo enviado el 25/07/2019 Artículo aceptado el 05/12/2019 